\title{
Growth and Income Inequality: A Comparative Analysis
}

\author{
Ayla Ogus Binatli \\ Department of Economics, Izmir University of Economics, Sakarya Cad. No.156, Balcova, 35330 Izmir, Turkey \\ Correspondence should be addressed to Ayla Ogus Binatli, ayla.ogus@ieu.edu.tr
}

Received 16 August 2011; Revised 10 December 2011; Accepted 10 December 2011

Academic Editor: Russell Smyth

Copyright ( 2012 Ayla Ogus Binatli. This is an open access article distributed under the Creative Commons Attribution License, which permits unrestricted use, distribution, and reproduction in any medium, provided the original work is properly cited.

\begin{abstract}
This paper investigates whether the relationship between income inequality and growth changes over time. Two time periods, covering 1970-1985 and 1985-1999, are analyzed and compared. A statistically significant relationship between inequality and growth in either time period fails to emerge. However, there are indications that effect of inequality on growth may be different in the nineties when compared to the seventies. In the literature, a consistent negative effect of inequality on growth is documented although the significance of the effect is open to debate. This paper also finds a negative effect of income inequality on growth in the seventies but, although statistically insignificant, a consistently positive effect in the nineties.
\end{abstract}

\section{Introduction}

The relationship between income inequality and growth is dubious at best. Even though most of the empirical evidence by the mid-nineties suggested that there was a negative relationship between income inequality and growth, Weede [1] put to test previous findings to conclude that the adverse effect of income inequality on growth could not be established. Later work has done little to resolve the issue. A vast proportion of the empirical work is based on crosscountry evidence for the period from 1960 to 1985, and some studies extend the analysis to 1990 [2]. However, the nineties as the crest of the age of globalization are tainted by several economic crises, which undoubtedly have implications for income inequality. Therefore, it might be possible to find a robust link between income inequality and growth if a later time period is the focus of analysis.

The existing empirical evidence does not shed light on whether there exists a robust relationship between income inequality and growth in the nineties or whether the income inequality and growth relationship has changed over time. This paper will attempt to determine if the determinants of growth and income inequality have changed over time. In doing so, it adds to the empirical cross-country evidence on the income inequality and growth relationship by providing a comparison of the 1960-1985 period with the 1985-1999 period where income distribution of countries have changed for the worse.

\section{Literature Review}

The relationship between income inequality and growth is dubious. Even though by the mid-nineties, there existed a substantial body of empirical research that suggested that there was a negative effect on growth of income inequality [3-9]. Benabou [10] provides a thorough review of these earlier empirical findings. Weede [1] questioned the robustness of earlier findings and showed that based on existing evidence, it was not possible to claim a robust relationship between income inequality and growth. Moreover, other researchers scrutinized the quality of income distribution data. Deininger and Squire [11] performed a quality test of available data and investigated the growth income inequality tradeoff based on quality-controlled datasets, which failed to exhibit a significant relationship of income inequality on growth. Consensus has been elusive in the more recent literature as well. Ghura et al. [12] tested the Kuznetz hypothesis on growth and income inequality and found no evidence supporting a robust relationship between growth and income inequality. On the other hand, MacDonald and Majeed [13] regress the Gini coefficient on GDP and squared GDP for the period from 1970 to 2008, and they find a robust relationship with or without controlling for government expenditure levels and human capital among other things. Dollar and Kray [14] showed that the income of the poorest segment of the population changed in relation to average income and argued that there was no relationship 
between income inequality and growth, but rather, growth affected the absolute income of the poor. Weisbrot et al. [15] argued that neither the poor nor the wage earners were able to exploit the returns from growth. Tabassum and Majeed [16], in their sample of 69 developing countries, show that inequality may help growth in the short run but will hamper it in the long run.

The effect of growth on income inequality is also under debate. Pardo-Beltran [2] argued that growth affected income inequality negatively but this effect was nonlinear, which is also indicated in García-Peñalosa and Turnovsky [17] in the context of an endogenous growth model. Breen and García-Peñalosa [18], Hausman and Gavin [19], and Oğuş [20] showed that volatility of growth was detrimental for income inequality.

Most of the aforementioned papers utilize data on the average growth rates between 1960 and 1990. A few have extended the analysis to 2003. In this paper, the effect of growth on income inequality and vice versa will be compared and contrasted for two different time periods.

\section{Data}

The Gini coefficients and quintile shares were obtained from the World Income Inequality Database (WIID) put together by the United Nations Development Programme (UNDP). The macroeconomic and socioeconomic variables are from the World Bank World Development Indicators Database (WDID). In most published work, the average growth rates for 25-year periods were used and the time frame of analysis is mostly 1960-1985 [4, 8]. Other studies have looked at the 15-year average growth rates for the time period (19701985) [2]. To be able to compare these results with published findings, three samples covering 1960-1975, 1960-1985, and 1970-1985 are constructed. The analysis of the latter time period is based on a sample that covers 1985-1999. Since results obtained from the three samples for the earlier time period did not differ in any substantial way, in the paper only descriptive statistics and regression results based on the 1970-1985 period will be presented as this is the largest sample among the three.

In the WIID, there are 5067 observations for 151 countries for the years 1958-1999. 2185 of these observations are considered reliable. There are 5050 observations for Gini coefficients and 1762 observations for quintile shares. The samples used in this paper only include reliable observations for which information on the Gini coefficient and quintile shares are both available. Therefore, the samples are somewhat small. For 1970-1985 there are 42 observations and for 1985-1999 the sample has 49 observations.

The income distribution data are gathered for 5-year periods. For example, the 1985 income distribution data consist of observations covering 1983-1987. Most countries perform income distribution surveys once every few years. Restricting the sample to only surveys conducted in a single year would have reduced sample size considerably. The growth rates are for real GDP per capita. Volatility is the standard deviation of real GDP per capita. Real GDP per capita, public expenditure as a ratio of GDP, enrollment rates are from the WDID.

Table 1 presents the descriptive statistics on the variables for 1970-1985 and 1985-1999, respectively. The mean real GDP per capita in 1970 is $\$ 5591$ compared to $\$ 9751$ in 1999. Mean average growth rate for the earlier time period is $2.13 \%$ compared to $2.04 \%$ for the later sample. Although mean growth rates are quite similar, the standard deviation of average growth rates differ substantially between the two samples. The standard deviation of average growth rates is 0.86 for $1970-1985$ as opposed to 1.83 for $1985-1999$. The volatility of growth rates is 3.53 and 3.22 for the first and second sample, respectively. Fertility rates have dropped from 3.87 to 2.80. Enrollment rates in all levels of education increase over time. The mean enrollment rate in primary education in the $1985-1999$ period is $99 \%$ compared to $96 \%$ for the earlier sample. The improvement in the enrollment in primary education is reflected in the decrease in the standard deviation of the enrollment rates to 15 percent for 19851999 compared to 22 percent for the 1970-1985 period. Government expenditures as a percentage of GDP are 14 percent on average for the sample covering 1970-1985 and 16 percent for the later time period.

The Gini coefficient for the earlier period is 42.29 compared to 37.46 for the later period. The other income inequality measures also indicate a better income distribution for the later sample. When income inequality at the beginning of the sample period is compared with the end of the period, it becomes apparent that in the 1970-1985 period a relatively large improvement in income inequality has taken place. The Gini coefficient is 37.62 at the end of the sample period compared to 42.29 at the beginning of the sample. The share of income of the wealthiest quintile was 12 times larger than the income share of the poorest quintile in 1970; it had fallen to 8.1 by the end of the sample period. The income share of the wealthiest quintile was 4 times greater than the income share of the first and second quintiles combined in 1970; it had fallen to 2.8 times by 1985 . In the 1985-1999 time period there is no change in income inequality of this magnitude.

The reader is referred to Oğuş $[20,21]$ for a comparison of inequality measures for 1987 and 1999 which constitute more evidence for this argument.

\section{The Effect of Income Inequality on Growth}

This section investigates whether the effect of income distribution on growth has changed over time. To this end, the relationship between the historical long-term average growth rates and income inequality for the samples covering 1970-1985 and 1985-1999 will be discussed.

Table 2 presents regression results for a growth equation with income inequality and other possible determinants of growth. The results for average growth rates of 1970-1985 are directly comparable to existing studies and are consistent with their findings. Regional dummy variables for Africa and Latin America, enrollment in primary education, and fertility rates are statistically significant. Growth rates in Africa and Latin America, when all else is assumed constant, are 
TABLE 1: Descriptive statistics.

\begin{tabular}{|c|c|c|c|c|c|}
\hline \multirow{3}{*}{ Sample } & \multicolumn{2}{|r|}{ I } & \multicolumn{2}{|r|}{ II } & \\
\hline & \multicolumn{2}{|c|}{$1970-1985$} & \multicolumn{2}{|c|}{ 1985-1999 } & \\
\hline & Mean & Std error & Mean & Std Error & \\
\hline GDP & 5591 & 6145 & 9751 & 9856 & GDP per capita at the beginning of the period in 1995 US\$ \\
\hline FER & 3.87 & 1.65 & 2.80 & 1.41 & Number of children per women (average rate for 1970-1985) \\
\hline GOVT & 13.92 & 4.47 & 15.81 & 6.18 & Average government expenditures as a percentage of GDP \\
\hline PRIM & 95.76 & 22.16 & 98.69 & 15.22 & Primary school enrollment (time period average per 100 school age children) \\
\hline SEC & 45.03 & 25.42 & 64.89 & 29.61 & Secondary school enrollment (average per 100 school age children) \\
\hline TER & 10.60 & 11.24 & 19.40 & 14.93 & Tertiary school enrollment (average per 100 school age children) \\
\hline VOL & 3.53 & 1.49 & 3.22 & 2.06 & Standard error of average growth rate of GDP per capita \\
\hline GROWTH & 2.13 & 0.86 & 2.04 & 1.83 & Average growth rate of GDP per capita \\
\hline GINI & 42.29 & 10.31 & 37.46 & 9.13 & Gini coefficient at the beginning of the period \\
\hline Q1 & 0.05 & 0.02 & 0.06 & 0.02 & Share of 1st quintile at the beginning of the period \\
\hline Q2 & 0.10 & 0.03 & 0.11 & 0.03 & Share of 2 nd quintile at the beginning of the period \\
\hline Q3 & 0.15 & 0.03 & 0.16 & 0.02 & Share of 3rd quintile at the beginning of the period \\
\hline Q4 & 0.22 & 0.03 & 0.22 & 0.02 & Share of 4 th quintile at the beginning of the period \\
\hline Q5 & 0.49 & 0.09 & 0.45 & 0.08 & Share of 5 th quintile at the beginning of the period \\
\hline Q5/Q1 & 12.33 & 8.65 & 8.65 & 6.01 & At the beginning of the period \\
\hline $\mathrm{Q} 5 /(\mathrm{Q} 1+\mathrm{Q} 2)$ & 3.95 & 2.47 & 2.86 & 1.52 & At the beginning of the period \\
\hline $\mathrm{Q} 2+\mathrm{Q} 3$ & 0.24 & 0.05 & 0.27 & 0.05 & At the beginning of the period \\
\hline GINI* & 37.62 & 8.86 & 37.92 & 9.46 & Gini coefficient at the end of the period \\
\hline Q5/Q1* & 8.10 & 4.49 & 8.18 & 5.29 & At the end of the period \\
\hline $\mathrm{Q} 5 /(\mathrm{Q} 1+\mathrm{Q} 2)^{*}$ & 2.77 & 1.39 & 2.85 & 1.47 & At the end of the period \\
\hline $\mathrm{Q} 2+\mathrm{Q} 3 *$ & 0.27 & 0.05 & 0.26 & 0.05 & At the end of the period \\
\hline AFRICA & 0.15 & 0.37 & 0.13 & 0.33 & 1 for countries in Africa \\
\hline LATIN & 0.23 & 0.43 & 0.15 & 0.36 & 1 for countries in Latin America \\
\hline
\end{tabular}

Sample 1 (1970-1985; 42 observations): Australia, Bangladesh, Bolivia, Brazil, Bulgaria, Canada, Chile, Colombia, Costa Rica, Ecuador, Fiji, France, Honduras, Hong Kong, Hungary, India, Ireland, Japan, Malaysia, Mexico, New Zealand, Norway, Pakistan, Panama, Philippines, Portugal, Puerto Rico, Sierra Leone, Spain, Sri Lanka, Sudan, Sweden, Thailand, Trinidad and Tobago, Tunisia, Turkey, United Kingdom, United States, Venezuela, Republic of Korea.

Sample 2 (1985-1999; 49 observations): Australia, Austria, Bahamas, Bangladesh, Belgium, Botswana, Brazil, Bulgaria, Canada, China, Costa Rica, Dominican Republic, Finland, France, Guatemala, Hong Kong, Hungary, India, Indonesia, Ireland, Israel, Italy, Japan, Jordan, Lesotho, Luxembourg, Malaysia, Mauritius, Mexico, Morocco, Nepal, The Netherlands, New Zealand, Nigeria, Norway, Pakistan, Peru, Philippines, Poland, Rwanda, Singapore, Spain, Sri Lanka, Sweden, Turkey, Ukraine, United Kingdom, United States, Venezuela.

lower by 1 percent. Primary school enrollment affect growth positively and fertility rates negatively. Alesina and Rodrik [4] and Perotti [8] have reached similar conclusions. GDP per capita at the beginning of the period does not determine average long-term growth rates. In growth models, initial value of GDP is included as a regressor to capture growth convergence. The Solow growth model predicts faster growth for countries which are capital poor as capital flows to these countries. This is convergence in the short run which reduces the gap between incomes for poor and rich countries. In the long run, absolute convergence can be achieved and the gap between incomes will be eliminated. De La Fuente [22] provides a comprehensive review.

There is no statistically significant relationship between growth and income inequality as measured by the Gini coefficient. It is possible to extend the model to include nonlinear effects and show that the Gini coefficient does have an impact on growth. But since the intent here is to compare the 1970s with the 1990s, the paper does not stray away from the most standard approaches. When the regional dummy variables are excluded from the regression,
$\overline{R^{2}}$ declines significantly. All the regressions were estimated without an intercept and thus $\overline{R^{2}}$ is provided as the only measure of goodness of fit.

When the regression results for the 1985-1999 period are compared with the earlier sample, there are major similarities but also important differences. In both time periods, the Latin America dummy variable and enrollment in primary education are statistically significant determinants of growth. GDP per capita and enrollment rates in secondary education are not. There is an indication that the effect of secondary education on growth is changing over time since the sign of the coefficient on this variable is significant for the 19701985 time period but negative in the later time period; this paper does not present enough evidence to reach stronger conclusions.

The effects of the other variables on growth rates have changed over time. The Africa dummy variable and fertility rates have lost significance over time as determinants of growth. The correlation between the Africa dummy variable and fertility rates is $66 \%$, and the Africa dummy only becomes significant if fertility rates are excluded from 
TABLE 2: The determinants of growth rate.

\begin{tabular}{|c|c|c|c|c|c|}
\hline & \multicolumn{2}{|c|}{ 1970-1985 } & \multicolumn{3}{|c|}{ 1985-1999 } \\
\hline & 1 & 2 & 1 & 2 & 3 \\
\hline \multirow{2}{*}{ GDP } & 0.00003 & 0.00003 & 0.00003 & 0.00003 & 0.00005 \\
\hline & $(0.00003)$ & $(0.00003)$ & $(0.00003)$ & $(0.00003)$ & $(0.00003)$ \\
\hline \multirow{2}{*}{ GINI } & -0.0215 & 0.0203 & 0.0377 & $0.0428^{*}$ & 0.0372 \\
\hline & $(0.0259)$ & $(0.0220)$ & $(0.0246)$ & $(0.0246)$ & $(0.0248)$ \\
\hline \multirow{2}{*}{ PRIM } & $0.0138^{* * *}$ & $0.0159^{* * *}$ & $0.0266^{* * *}$ & $0.0238^{* *}$ & $0.0350^{* * *}$ \\
\hline & $(0.0087)$ & $(0.0078)$ & $(0.0090)$ & $(0.0091)$ & $(0.0127)$ \\
\hline \multirow{2}{*}{ SEC } & 0.0113 & 0.0171 & & & -0.0179 \\
\hline & $(0.0163)$ & $(0.0174)$ & & & $(0.0141)$ \\
\hline \multirow{2}{*}{ TER } & -0.0030 & -0.0020 & $-0.0484^{* * *}$ & $-0.0513^{* * *}$ & $-0.0415^{* *}$ \\
\hline & $(0.0347)$ & $(0.0287)$ & $(0.0163)$ & $(0.0163)$ & $(0.0179)$ \\
\hline \multirow{2}{*}{ FER } & -0.1551 & $-0.1555^{* * *}$ & $-0.3488^{* *}$ & -0.2476 & -0.2812 \\
\hline & $(0.0989)$ & $(0.0700)$ & $(0.1564)$ & $(0.1720)$ & $(0.1727)$ \\
\hline \multirow{2}{*}{ AFRICA } & & $-1.1235^{* * *}$ & & -0.9402 & -1.1368 \\
\hline & & $(0.5977)$ & & $(0.6958)$ & $(0.7076)$ \\
\hline \multirow{2}{*}{ LATIN } & & $-1.1376^{* * *}$ & $-1.7113^{* * *}$ & $-1.8982^{* * *}$ & $-2.1166^{* *}$ \\
\hline & & $(0.5117)$ & $(0.5629)$ & $(0.5741)$ & $(0.5951)$ \\
\hline$\overline{R^{2}}$ & 0.39 & 0.49 & 0.41 & 0.43 & 0.45 \\
\hline
\end{tabular}

Notes: ${ }^{*}, * * * *$ denote 10,5 , and 1 percent significance respectively, standard errors are in parenthesis.

the regression as a possible determinant of growth and vice versa. Enrollment rates in tertiary education become a significant determinant of growth in the later time period with a negative sign. Higher education seems to be costly for growth. However, this is probably due to the fact that higher rates of enrollment in higher education take place in more developed countries where growth rates are lower.

The Gini coefficient remains insignificant for the later sample. However, the sign is consistently positive in all the models in contrast to an insignificant but negative effect of income inequality on growth for the earlier sample. As mentioned before, in the literature predominantly data between 1960 and 1985 are analyzed and a consistently negative relationship of income inequality on growth is documented [10].

4.1. Different Income Inequality Measures. There are different measures of income distribution. Gini coefficients are more readily available, therefore, in empirical work, have been the measure more frequently favored. However, especially theories of political economy concentrate on the median voter; therefore it is important to look at the relative wellbeing of this segment of the population. The share of the second and third quintiles combined is used to measure the well-being of the median voter here following published work. In the literature the share of the second and third quintile has been used more often than the share of the third quintile only.

In addition, the relative poverty of the lowest quintile is a great threat to political and social stability; therefore their well-being is also important. In this paper, the growthincome inequality relationship for these segments of the
TABLE 3: The correlation of the Gini coefficient and other measures.

\begin{tabular}{cccc}
\hline & Q5/Q1 & Q5/(Q1+Q2) & Q2 + Q3 \\
\hline 1960 & 0.78 & 0.89 & -0.88 \\
1970 & 0.68 & 0.72 & -0.70 \\
1985 & 0.72 & 0.89 & -0.91 \\
1999 & 0.84 & 0.89 & -0.94 \\
\hline
\end{tabular}

population is investigated as well. Three other income inequality measures are used. The ratio of the income share of the fifth quintile divided by the share of the first quintile (Q5/Q1) or the ratio of the income share of the fifth quintile divided by the share of the first and second quintile combined (Q5/(Q1 + Q2)) has been used as a measure of income inequality indicating relative poverty of the poorest segment of the population compared to the richest. Different income distributions based on these measures could produce similar Gini coefficients and large fluctuations in the income shares of certain segments of the population may result in negligible movements of the Gini coefficient. Therefore, the effect of growth on income inequality also for other measures of inequality is investigated.

Table 3 presents the correlation of the aforementioned three measures of income inequality with the Gini coefficient for various time periods. These income inequality measures are correlated with the Gini coefficient to varying degrees. However, correlation changes over time. The 1970s exhibits the lowest correlation in the Gini coefficient in the past four decades. Correlations have increased since 1970 and exceeded their 1960 levels by 1999. In 1999, the correlation of the first measure with the Gini coefficient was 0.84 in 
TABLE 4: Different income inequality measures and growth.

\begin{tabular}{|c|c|c|c|c|c|}
\hline & (1) & (2) & (3) & $(4)$ & $(5)$ \\
\hline \multirow{2}{*}{ GDP } & 0.00004 & 0.00003 & 0.00004 & 0.00003 & $0.00004^{*}$ \\
\hline & $(0.00003)$ & $(0.00003)$ & $(0.00003)$ & $(0.00003)$ & $(0.00003)$ \\
\hline \multirow{2}{*}{ GINI } & & & & 0.0377 & 0.0269 \\
\hline & & & & $(0.0246)$ & $(0.0223)$ \\
\hline \multirow{2}{*}{ Q5/Q1 } & 0.0346 & & & & \\
\hline & $(0.0329)$ & & & & \\
\hline \multirow{2}{*}{$\mathrm{Q} 2+\mathrm{Q} 3$} & & & -2.1106 & & \\
\hline & & & $(3.1476)$ & & \\
\hline \multirow{2}{*}{ Q5/(Q1 + Q2) } & & 0.1039 & & & \\
\hline & & $(0.1412)$ & & & \\
\hline \multirow{2}{*}{ PRIM } & $0.0297^{* * *}$ & $0.0347^{* * *}$ & $0.0395^{* * *}$ & $0.0266^{* * *}$ & $0.0221^{* * *}$ \\
\hline & $(0.0045)$ & $(0.0068)$ & $(0.0115)$ & $(0.0090)$ & $(0.0092)$ \\
\hline \multirow{2}{*}{ TER } & $-0.0551^{* * *}$ & $-0.0504^{* * *}$ & $-0.0524^{* * *}$ & $-0.0484^{* * *}$ & $-0.0520^{* * *}$ \\
\hline & $(0.0165)$ & $(0.0166)$ & $(0.0167)$ & $(0.0163)$ & $(0.0165)$ \\
\hline \multirow{2}{*}{ FER } & & $-0.2422^{*}$ & & $-0.3488^{* *}$ & \\
\hline & & $(0.1375)$ & & $(0.1564)$ & \\
\hline \multirow{2}{*}{ AFRICA } & $-1.2666^{* *}$ & & $-1.0004^{* *}$ & & $-1.3766^{* *}$ \\
\hline & $(0.6120)$ & & $(0.5833)$ & & $(0.6347)$ \\
\hline \multirow{2}{*}{ LATIN } & $-1.6954^{* * *}$ & $-1.5440^{* * *}$ & $-1.6166^{* * *}$ & $-1.7113^{* * *}$ & $-1.7555^{* * *}$ \\
\hline & $(0.5663)$ & $(0.5694)$ & $(0.5639)$ & $(0.5630)$ & $(0.5731)$ \\
\hline$\overline{R^{2}}$ & 0.32 & 0.30 & 0.31 & 0.33 & 0.40 \\
\hline
\end{tabular}

*\%10 significance, $* * \% 5$ significance, $* * * \% 1$ significance.

1999 , compared to a low of 0.68 in 1970 . The correlation of the second measure has been consistently 0.89 excluding the 1970s, when it had declined to 0.72 . The third measure has the highest correlation with the Gini, 0.94 in 1999, but in 1970 this correlation had also declined to 0.7 .

Given the varying levels of correlation between different income inequality measures and the Gini coefficient, it is interesting to investigate the relationship between income inequality and growth using different measures of income inequality. In Table 4 the regression results using different income inequality measures are presented.

Table 4 analyzes the determinants of average growth rate for 1985-1999 using real GDP per capita in 1985, income distribution in 1985, average rates of enrollment in secondary and tertiary education, and regional dummy variables. The income inequality measure used does not affect the significance of explanatory variables nor the overall fit. As before, enrollment rates in primary and tertiary education and the Latin America dummy variable are significant. The Africa dummy variable is significant in these regressions only because the fertility rate is not included as a regressor.

Average fertility rate is significant and the Africa dummy variable is left out as its significance disappears when the fertility rate is included. Note that, in the earlier time period, this is not the case; both the Africa dummy variable and the fertility rate are statistically significant determinants of growth. In summary, regardless of how income inequality is measured, there has been no change in the effect of income inequality on growth or lack of it.

\section{The Effect of Growth on Income Inequality}

The effect of growth on income distribution and whether this relationship changes over time are also investigated. G. Ramey and V. A. Ramey [23] argue that high volatility in growth rates leads to lower average growth rates. Hausman and Gavin [19] analyze Latin American countries and show that these countries are more volatile and exhibit greater inequalities in income distribution. The results presented here confirm these findings. Volatility in the growth rates rather than average growth rate is found to be a determinant of income inequality. The marginal effect of volatility on the Gini coefficient was four times larger for the 1970-1985 period.

Our focus is on the effect of volatility of growth on inequality and not the effect of growth on inequality. In their analysis of the effect of volatility of output on income inequality, Breen and García-Peñalosa [18] include the logarithm of initial value of GDP as well as its square in regressions with the standard deviation of output growth. The initial value of GDP and its square loses significance when the volatility of output is included. Hence, in our regressions, we include only the volatility of output growth. Thus, our regressions do not allow us to test the Kuznetz hypothesis and we do not contribute to the literature that investigates the effect of the level of development on income inequality.

Average growth rates, public expenditure as a ratio of GDP, enrollment rates, fertility rates, and volatility in growth are included as potential determinants of income inequality. In Table 5, income inequality is measured by the Gini 
TABLE 5: The effect of growth on income inequality.

\begin{tabular}{|c|c|c|c|c|c|c|c|c|}
\hline & GROWTH & VOL & GOVT & PRIM & SEC & TER & FER & $\overline{R^{2}}$ \\
\hline \multirow{2}{*}{ (1) } & & $1.3801^{* * *}$ & 0.4449 & $0.2254^{* * *}$ & -0.1061 & & $3.1227^{* * *}$ & 0.46 \\
\hline & & $(0.4788)$ & $(0.3582)$ & $(0.0608)$ & $(0.0907)$ & & $(1.0520)$ & \\
\hline \multirow{2}{*}{ (2) } & & $0.3754^{* * *}$ & 0.0125 & $0.3576^{* * *}$ & -0.1252 & & $3.2223^{* * *}$ & 0.43 \\
\hline & & $(0.1874)$ & $(0.2814)$ & $(0.0646)$ & $(0.0818)$ & & $(1.1569)$ & \\
\hline \multirow{2}{*}{ (3) } & & $0.3257^{* * *}$ & -0.0414 & $0.3662^{* * *}$ & $-0.1929 * *$ & 0.2138 & $3.2974^{* * *}$ & 0.46 \\
\hline & & $(0.1381)$ & $(0.2762)$ & $(0.0631)$ & $(0.0905)$ & $(0.1357)$ & $(1.1274)$ & \\
\hline \multirow{2}{*}{ (4) } & -0.0783 & 0.2739 & -0.0392 & $0.3703^{* * *}$ & $-0.1919^{* *}$ & 0.2054 & $3.2919 * * *$ & 0.44 \\
\hline & $(0.8533)$ & $(0.9409)$ & $(0.2826)$ & $(0.0787)$ & $(0.0928)$ & $(0.1657)$ & $(1.1511)$ & \\
\hline
\end{tabular}

White heteroskedasticity consistent standard errors are in parenthesis.

coefficient. The first model shows how the 1985 Gini coefficient is affected by 1970-1985 growth rates. Enrollment in primary education and fertility rates are the most significant determinants of income inequality. However, enrollment in primary education increases income inequality. Volatility of growth also increases income inequality. Breen and GarcíaPeñalosa [18] have found that volatility increased income inequality for the years 1960-1990. Konya and Mouratidis [24] find a relationship between income inequality and growth based on cross-section evidence but cannot confirm it with panel data. The results presented here are consistent with their findings.

The dependent variable for the second, third, and fourth models are the Gini coefficient in 1999. Growth rates are for 1985-1999. The important difference here is the significance of enrollment in secondary education in all specifications. Researchers who investigate the determinants of wage inequality have found that skills are the most important factor in reducing inequality in wages. Therefore, it can be argued that enrollment rates in higher levels of education will continue to be significant factors in reducing income inequality in the future.

\section{Conclusion}

The relationship between income inequality and growth is still ambiguous. In empirical work, mostly due to unreliable data and the complex relationship between income inequality and growth, consensus has been evasive. This paper contributes to the literature on the empirics of the effect of income inequality on growth by providing a comparison of the 1985-1999 period with earlier periods. This analysis shows that the negative influence of income inequality on growth may be due to the dominating effect of data prior to 1985. The comparison of two time periods also indicates a changing relationship between economic volatility and income inequality. Volatility of output used to have a much larger effect on income inequality than it does since 1985.

Empirical analysis suggests that the effect of income distribution on economic growth in the nineties may be positive which supports the hypothesis that income inequality may facilitate faster growth in the short run. The Classical and Neoclassical economists argued that a more egalitarian income distribution would lead to lower savings, which would hamper investment and thus lead to slower growth. Endogenous growth theory, on the other hand, maintains that income inequality is bad for growth as it leads to social unrest which could create political instability. In the literature, a consistent negative effect of inequality on growth is documented although the significance of the effect is open to debate. This paper argues that this effect may be due to dominating effect of data from before the nineties.

The effect of growth on income inequality over time is also investigated. In both periods, enrollment in primary education and fertility rates are significant determinants of income inequality. Volatility of growth increases income inequality and the magnitude of the effect decreases over time. In the latter time period, 1 percent increase in the volatility of growth increases the Gini coefficient by 0.3 whereas in the former 1 percent increase would result in a Gini coefficient that is higher by 1.3 points.

\section{References}

[1] E. Weede, "Income inequality, democracy and growth reconsidered," European Journal of Political Economy, vol. 13, no. 4, pp. 751-764, 1997.

[2] E. Pardo-Beltran, Effects of Income Distribution on Growth, CEPA Working Paper 2002-16, Center for Economic Policy Analysis, 2002.

[3] A. Alesina and R. Perotti, "Income distribution, political instability, and investment," European Economic Review, vol. 40, no. 6, pp. 1203-1228, 1996.

[4] A. Alesina and D. Rodrik, "Distributive politics and economic growth," Quarterly Journal of Economics, vol. 109, no. 2, pp. 465-490, 1994.

[5] F. Bourguignon, "Growth, distribution, and human resources," in En Route to Modern Growth, G. Ranis, Ed., John Hopkins University Press, Baltimore, Md, USA, 1994.

[6] G. R. G. Clarke, More Evidence on Income Distribution and Growth, World Bank Working Paper 1064, World Bank Publications, Washington, DC, USA, 1992.

[7] R. Perotti, "Income distribution and investment," European Economic Review, vol. 38, no. 3-4, pp. 827-835, 1994.

[8] R. Perotti, "Growth, income distribution, and democracy: what the data say," Journal of Economic Growth, vol. 1, no. 2, pp. 149-187, 1996.

[9] T. Persson and G. Tabellini, "Is inequality harmful for growth?” American Economic Review, vol. 84, no. 3, pp. 600621, 1994. 
[10] R. Benabou, Inequality and Growth, NBER Working Paper 5658, National Bureau of Economic Research, Cambridge, Mass, USA, 1996.

[11] K. Deininger and L. Squire, "A new data set measuring income inequality," World Bank Economic Review, vol. 10, no. 3, pp. 565-591, 1996.

[12] D. Ghura, C. A. Leite, and C. Tsangarides, "Is growth enough? macroeconomic policy and poverty reduction," IMF Working Paper, no 118, 2002.

[13] R. MacDonald and M. T. Majeed, "Distributional and poverty consequences of globalization: a dynamic comparative analysis for developing countries," Working Papers, Business School-Economics, University of Glasgow, 2010 http:// econpapers.repec.org/RePEc:gla:glaewp:2010_22.

[14] D. Dollar and A. Kray, "Growth is good for the poor," The World Bank Development Research Group, 2000.

[15] M. Weisbrot, M. D. Baker, R. Naiman, and G. Neta, Growth May Be Good for the Poor-But are IMF and World Bank Policies Good for Growth? A Closer Look at the World Bank's Most Recent Defense of Its Policies, Center for Economic Policy Research, London, UK, 2000.

[16] A. Tabassum and M. T. Majeed, "Economic growth and income inequality relationship: role of credit market imperfection," Pakistan Development Review, vol. 47, no. 4, pp. 727743, 2008.

[17] C. García-Peñalosa and S. J. Turnovsky, "Growth and income inequality: a canonical model," Economic Theory, vol. 28, no. 1, pp. 25-49, 2006.

[18] R. Breen and C. García-Peñalosa, "Income inequality and macroeconomic volatility: an empirical investigation," Review of Development Economics, vol. 9, no. 3, pp. 380-398, 2005.

[19] R. Hausman and M. Gavin, "Securing stability and growth in a shock prone region: the policy challenges for latin america," in Securing Stability and Growth in Latin America, R. Hausman and H. Reisen, Eds., OECD, Paris, France, 1996.

[20] A. Oğuş, "The growth income inequality relationship in Turkey," in Proceedings of the 4th Economics Congress of Turkey, İzmir, Turkey, 2004.

[21] A. Oğuş, "Income distribution in Turkey," İktisat Işsletme ve Finans, vol. 20, no. 236, pp. 27-40, 2005.

[22] A. De La Fuente, "The empirics of growth and convergence: a selective review," Journal of Economic Dynamics and Control, vol. 21, no. 1, pp. 23-73, 1997.

[23] G. Ramey and V. A. Ramey, "Cross-country evidence on the link between volatility and growth," American Economic Review, vol. 85, no. 5, pp. 1138-1151, 1995.

[24] L. Konya and C. Mouratidis, "An empirical analysis of the relationship between income inequality and growth volatility in 70 countries for 1960-2002," Applied Econometrics and International Development, Euro-American Association of Economic Development, vol. 8, no. 1, pp. 19-40, 2006. 


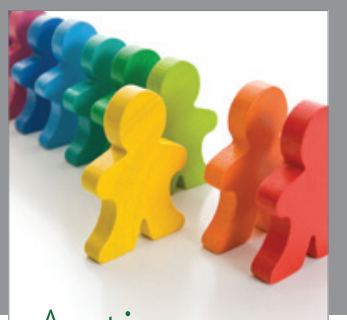

Autism

Research and Treatment
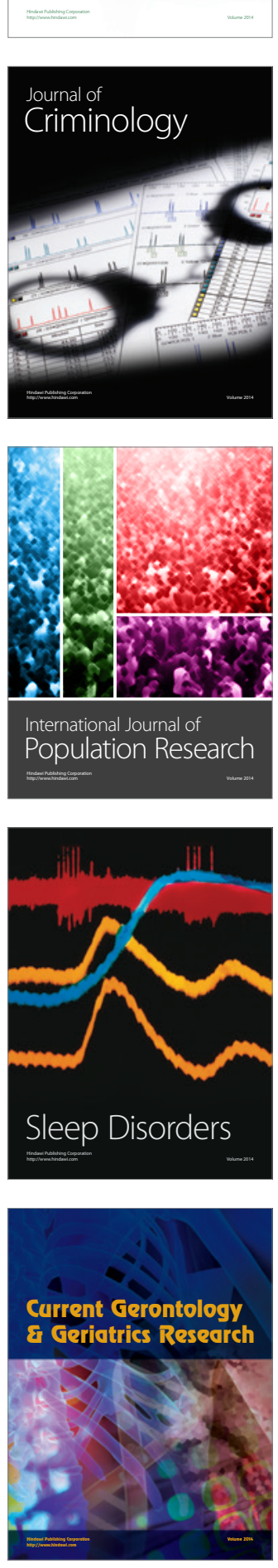
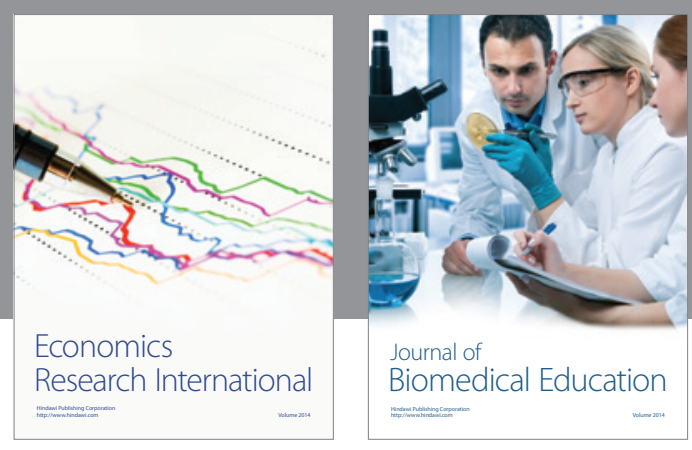

Journal of

Biomedical Education

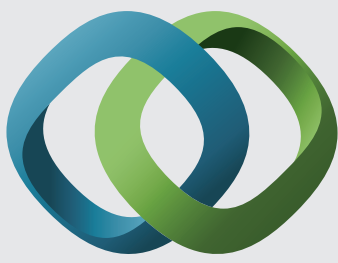

\section{Hindawi}

Submit your manuscripts at

http://www.hindawi.com
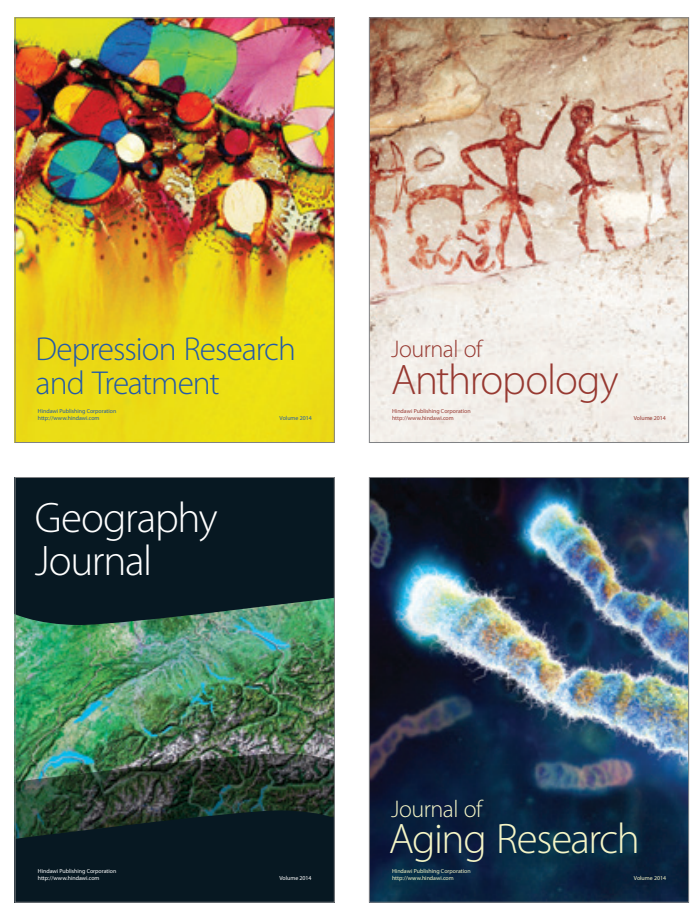

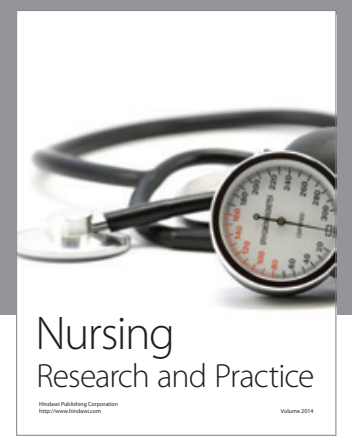

Nursing

Research and Practice

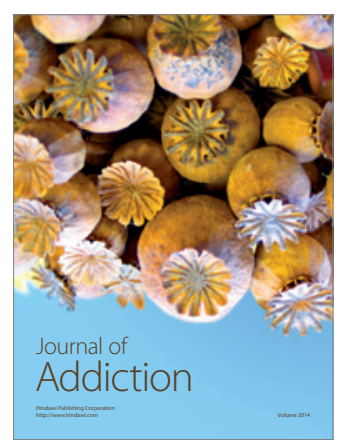

Child Development

Research

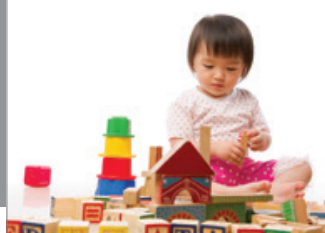

迥
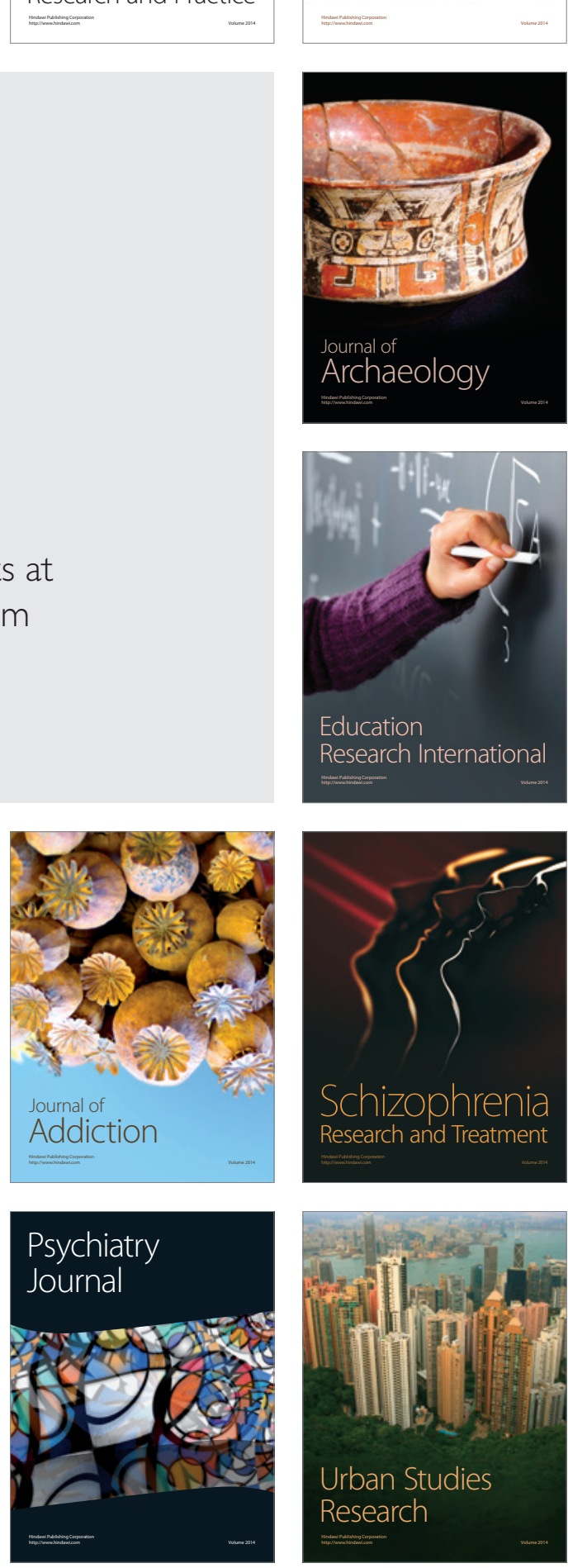